\title{
ANÁLISE DOS MEMORIAIS DESCRITIVOS DOS MUNICÍPIOS DO ESTADO DO AMAPÁ - O CASO DE PORTO GRANDE, CALÇOENE E AMAPÁ
}

Edivan Oliveira da Silva ${ }^{1}$

Universidade Federal do Amapá

Fabiano Luís Belém²

Universidade Federal do Amapá

Enviado em 30 out. 2020 | Aceito em 1 fev. 2021

Resumo: O presente trabalho apresenta uma análise dos memoriais descritivos dos municípios de Porto Grande, Calçoene e Amapá, do estado do Amapá. Estes memoriais influenciam diretamente sobre os limites legais dos municípios, suas áreas de abrangência e na materialização de seus perímetros. Para realizar o estudo seguiu-se os procedimentos metodológicos. Primeiramente, a espacialização dos marcos geodésicos descritos nos memoriais descritivos no Sistema de Informação Geográfica. Depois realizou-se a conferência do que foi especializado com o que estava no memorial descritivo. 0 objetivo do trabalho é retratar a realidade existente no que concerne às questões relacionadas às divisas municipais utilizando as geotecnologias para a identificação de incompatibilidade no que tange ao memorial descritivo e a base cartográfica existente. Como resultado foi possível identificar várias inconsistências no decorrer da espacialização dos limites municipais de Porto Grande, Calçoene e Amapá. A partir das informações contidas nos memoriais descritivos, mostrando assim, a necessidade de revisão dos limites municipais.

Palavras-chave: Limite municipal; Espacialização; Geotecnologias; Cartografia.

\section{ANALYSIS OF THE DESCRIPTIVE MEMORIALS OF THE MUNICIPALITIES OF THE STATE OF AMAPÁ- THE CASE OF PORTO GRANDE, CALÇOENE AND AMAPÁ}

Abstract: This paper presents an analysis of the descriptive memorials of the municipalities of Porto Grande, Calçoene and Amapá in the state of Amapá. These memorials directly influence the legal limits of the municipalities, their areas of coverage and the materialization of their perimeters. To carry out the study, methodological procedures were followed. First, the spatialization of the geodesic landmarks described in the descriptive memorials in the Geographic Information System. Then there was a conference of what was specialized with what was in the description. The objective of the work is to portray the existing reality with respect to issues related to municipal boundaries using geotechnologies to identify incompatibility with regard to the descriptive memorial and the existing cartographic base. As a result, it was possible to identify several inconsistencies during the spatialization of the municipal limits of Porto Grande, Calçoene and Amapá. From the information contained in the descriptive memorials, thus showing the need to revise the municipal limits.

Keywords: Municipal boundaries; Spacialization; geotechnologies; cartography.

\section{ANÁLISIS DE LAS MEMORIAS DESCRIPTIVAS DE LOS MUNICIPIOS DEL ESTADO DE AMAPÁ - EL CASO DE PORTO GRANDE, CALÇOENE Y AMAPÁ}

Resumen: El presente trabajo presenta un análisis de los memoriales descriptivos de los municipios de Porto Grande, Calçoene y Amapá, en el estado de Amapá. Estos memoriales inciden directamente en los límites legales de los municipios, sus áreas de cobertura y la materialización de sus perímetros. Para la realización del estudio se siguieron procedimientos metodológicos. Primero, la espacialización de los hitos geodésicos descritos en los memoriales descriptivos en el Sistema de Información Geográfica. Luego hubo una conferencia de lo especializado con lo que estaba en la descripción. El objetivo del trabajo es retratar la realidad existente con respecto a cuestiones relacionadas con los límites municipales utilizando geotecnologías para identificar incompatibilidades con respecto al memorial descriptivo y la base cartográfica existente. Como resultado, fue posible identificar varias inconsistencias durante la espacialización de los límites municipales de Porto Grande, Calçoene y Amapá. A partir de la información contenida en los memoriales descriptivos, evidenciando así la necesidad de revisar los límites municipales.

Keywords: límite municipal; Espacialización; Geotecnologías; Cartografía.

1. Estudante de Licenciatura em Geografia da Universidade Federal do Amapá. ORCID: https://orcid.org/0000-0002-52899076. Email: edivanolvra@gmail.com.

2. Professor da Universidade Federal do Amapá. Doutor em Geografia pela Universidade Federal de Goiás. ORCID: https://orcid.org/0000-0003-0858-0399. E-mail: fbl.geo@gmail.com. 
Introdução

Os municípios são as menores unidades autônomas da organização territorial brasileira. A sua incorreta delimitação acarreta em impactos sociais, econômicos, fiscais, dentre outros. Este é um processo dinâmico que envolve diversos atores. De acordo com Borges et al. (2015), os limites oficiais dos municípios brasileiros, em sua grande maioria, foram definidos por meio de referências e acidentes geográficos bem caracterizados existentes na época de criação dos municípios.

Com o desenvolvimento das tecnologias de mapeamento e a popularização espacial, muitas representações cartográficas passaram a ser rotuladas como antiquadas, isto se deve a possibilidade de constatar evidências espaciais com maior rapidez e confiabilidade mediante a popularização dos Sistemas de Informações Geográficas (SIG) e dos produtos de Sensoriamento Remoto.

A crescente importância do uso do Sensoriamento Remoto como fonte atualizada de dados para serem utilizados nos Sistemas de Informações Geográficas se deve, principalmente a dois fatores: ao surgimento de sensores instalados em plataformas orbitais trabalhando com resoluções cada vez mais sofisticadas; e ao grande volume de dados sobre o espaço terrestre que os equipamentos sensores vêm produzindo ao longo das últimas décadas (Ferreira, 2005).

Macedo et al. (2013) afirma que, a evolução da tecnologia relacionada a Cartografia, as geotecnologias, proporcionaram meios eficientes para se construir, atualizar e monitorar as informações espaciais, possibilitando maior agilidade na sua coleta, representação, distribuição e divulgação à sociedade.

É notório que a definição dos limites municipais legais é de fundamental importância no gerenciamento das ações governamentais, tendo em vista a delimitação espacial do aparelhamento político-administrativo que e bastante relevante para a gestão territorial. Silva et al. (2017), salienta que uma vez que estes memoriais se referem a elementos da superfície física terrestre, documentos cartográficos são utilizados para auxiliar na compreensão e interpretação da legislação.

No que se refere aos limites municipais do estado do Amapá, em cada lei municipal, há um memorial descritivo dos limites, que costumas ser definidos com base em elementos naturais, como cursos d'água, cabeceira/ foz de rios, ou ainda artificiais, tais como marcos de divisa, como as rodovias.

Foi verificado a inconsistência entre o descrito na lei, e o observado nos documentos cartográficos sobre a área objeto de investigação. Tecnicamente, foram identificadas incompatibilidades entre a redação das leis, no que tange ao memorial descritivo e sua realização com compatibilidade na cartografia existente.

$\mathrm{Na}$ análise das leis e dos limites municipais, foram encontradas graves inconsistências nas leis de criação que não são possíveis de serem delimitadas no espaço, processos antiquados de levantamentos são responsáveis por muitas dessas inconsistências, pois as leis datam em sua maioria dos anos de 1950 e 1960. Entretanto há memoriais que datam de 1990, e mesmo estes sendo mais recentes apresentam diversas inconsistências. O uso de Legislação esparsa, de épocas diferentes, sem consolidações periódicas, o surgimento de novos municípios sem a atualização dos memoriais descritivos daqueles municípios já existentes gera grande dificuldade de entendimento.

Como agravante dessa situação, existem leis nas quais trechos da divisa e elementos cartográficos são referidos de forma incompleta, equivocada ou fora do sentido, em que as feições geográficas são colocadas de maneira errada, ocasionando pendências técnicas e/ou descontinuidade no traçado dos limites. 
Esse trabalho é fruto da parceria entre o projeto de Extensão Escritório Modelo de Geoprocessamento e a Secretaria de Estado do Meio Ambiente (SEMA), e tem por objetivo retratar a realidade existente no que concerne às questões relacionadas às divisas municipais do Estado do Amapá, tendo em vista as mais complexas particularidades envolvendo a referida malha de divisas, utilizando as geotecnologias para a identificação de incompatibilidade no que tange ao memorial descritivo e a base cartográfica existente, propondo assim, um ajuste nos memoriais descritivos de acordo com os limites já estabelecidos pelo IBGE (Instituto Brasileiro de Geografia e Estatística).

\section{Procedimentos metodológicos}

No que concerne aos passos metodológicos do trabalho, é realizada a interpretação e análise dos memoriais descritivos e do material cartográfico. Os memoriais descritivos dos municípios Porto Grande, Calçoene e Amapá são respectivamente dos anos 1992, 1956 e 1956. O material cartográfico utilizado neste trabalho são imagens de radar dos municípios estudados realizados pelo Departamento de Serviço Geográfico (DSG) através da Bradar. Este mapeamento foi feito com a banda P e X com uma resolução espacial de 1 metro (Vieira, 2015). Utilizou-se para auxílio a hidrografia destes municípios confeccionados pelo DSG e validados pela Secretaria de Meio Ambiente do estado do Amapá (SEMA-AP).

Após isto realizou-se a espacialização dos limites propostos nos memoriais descritivos dos municípios de Porto Grande, Calçoene e Amapá sobre as imagens de radar. A partir disso, detectou a divergência entre o que estava proposto pelo IBGE e entre o que estava escrito no memorial descritivo. Após isto realizou-se considerações sobre nova proposta de memoriais descritivos.

Os procedimentos metodológicos usados também incorporaram técnicas de geoprocessamento como vetorização de dados, métodos de sensoriamento remoto como interpretação de imagens de satélite. Para o processamento de dados e geração de mapas usou-se o software ARCGIS 10.3 conforme a figura 1.

Figura 1 - Fluxograma do método do trabalho

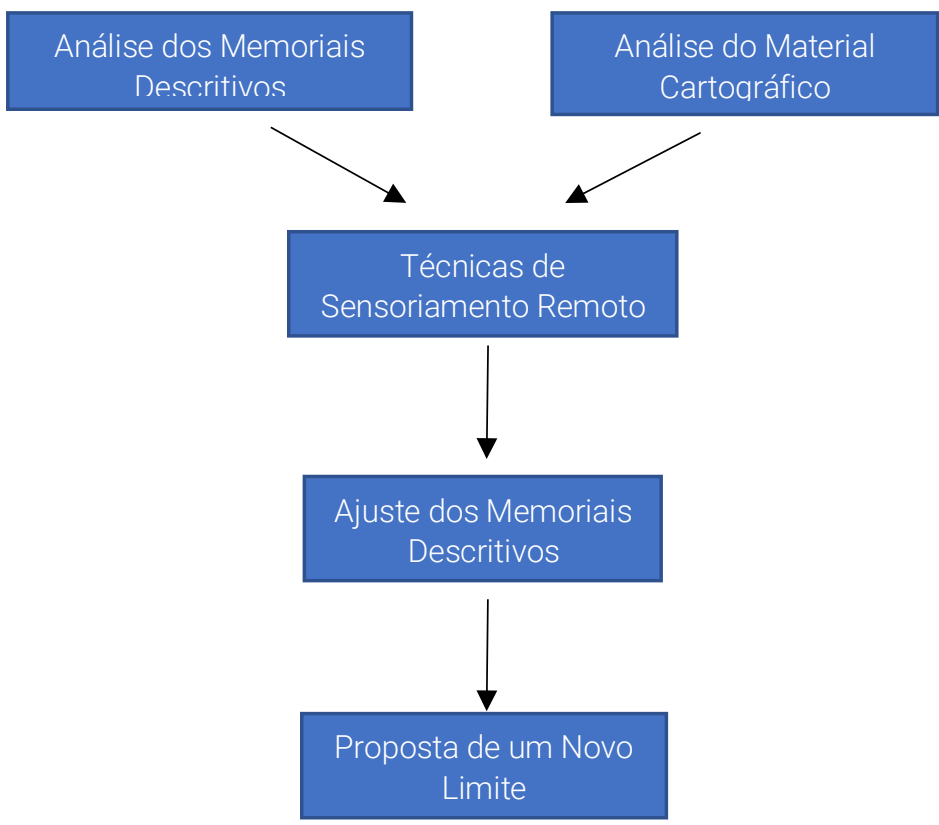

Fonte: Elaborado pelos autores. 


\section{Resultados}

O Amapá foi desmembrado do estado do Pará em 1943, e desde então foi se formando a sua malha de divisas municipais, estando atualmente com 16 municípios (Figura 2). Sendo que o município de Amapá foi criado em 1901 devido ao litígio entre a Franca e Brasil pela demarcação da fronteira. A partir disso, cria-se o município de Amapá para ocupação do território nacional e primeira capital do território do Amapá (Drummond; Pereira, 2007). O município de Calçoene foi criado em 1956 a partir da emancipação da Vila de Calçoene do município de Oiapoque. Já o município de Porto Grande foi criado em 1993 com a emancipação do município de Macapá (Drummond; Pereira, 2007).

Figura 2 - Formação Territorial do Amapá no decorrer dos anos

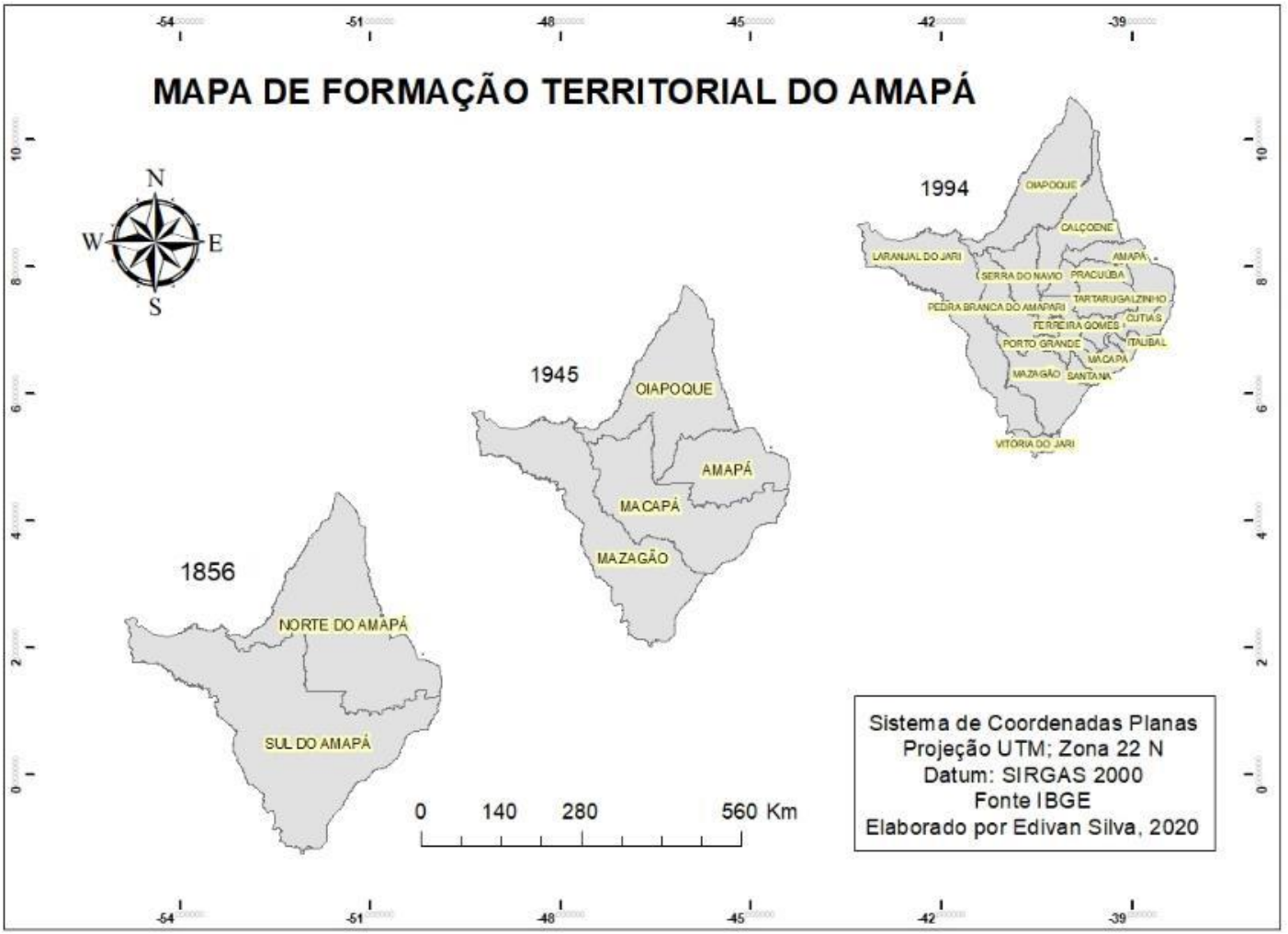

Fonte: IBGE. Organizado pelos autores.

Analisando os elementos do conteúdo dos memoriais descritivos dos municípios do estado do Amapá, que complementam os elementos cartográficos na delimitação dos polígonos, os mais frequentes foram: Hidrografia (rios e igarapés), Rodovias e em alguns casos coordenadas geográficas definidoras dos vértices dos municípios, entretanto, foi notado que algumas coordenadas não caiam no ponto em que se referia o memorial descritivo do município.

Foi observado que os limites são meramente político territoriais e definidos na forma de uma linguagem inadequada. Assim, ocorrem muitos equívocos cartográficos na definição das linhas divisórias por conta da linguagem utilizada na identificação de elementos da paisagem natural.

Alguns destes elementos apresentam mais dificuldade no traçado do polígono, como divisor de águas (que pode variar de acordo com o material/pessoal que realiza sua definição e traçado), 
hidrografia (pode sofrer alterações ao longo do tempo, seja ela oriunda de causas naturais ou não). De todos os elementos analisados, o que menos tem impacto no traçado e materialização são as estradas, rodovias, cuja alteração do traçado é difícil ao longo do tempo.

\section{Estudos de caso}

Objetivando retratar a complexidade que há na definição dos vértices dos limites que compõem a malha de divisas do estado do Amapá, aborda-se a seguir, uma análise da legislação definidora de 3 municípios do Estado (Porto Grande, Amapá e Calçoene), retratando algumas inconsistências que existem na definição dos limites municipais.

Para a identificação dessas inconsistências foi analisado o memorial descritivo dos 3 municípios mencionados e a partir desse estudo foi feito o traçado do polígono dos municípios utilizando a base cartográfica de hidrografia de 1:25.000 e 1:50.000, e base dos limites municipais disponibilizada pelo IBGE.

\section{Análise do memorial descritivo do município de Porto Grande}

O memorial descritivo do município de porto Grande data de maio de 1992, da lei nº 0003. Apesar de ser um município novo, o mesmo apresenta diversas inconsistências nas feições geográficas, como nas coordenadas definidoras do vértice do município, como por exemplo o seguinte trecho: "...por uma reta alcança a nascente do igarapé Manoel jacinto ponto de coordenadas geográficas aproximadas $00^{\circ} 52^{\prime} 32^{\prime \prime} \mathrm{N}$ e $051^{\circ} 30^{\prime} 13^{\prime \prime} \mathrm{W}$. Gr.". a partir da espacialização realizada foi observado que o referido ponto está a $8,10 \mathrm{~km}$ da real nascente do Igarapé Manoel jacinto (figura 3) estando assim, em desacordo com o memorial.

Figura 3 - Distância da nascente do igarapé Manoel Jacinto a coordenada citada no memorial

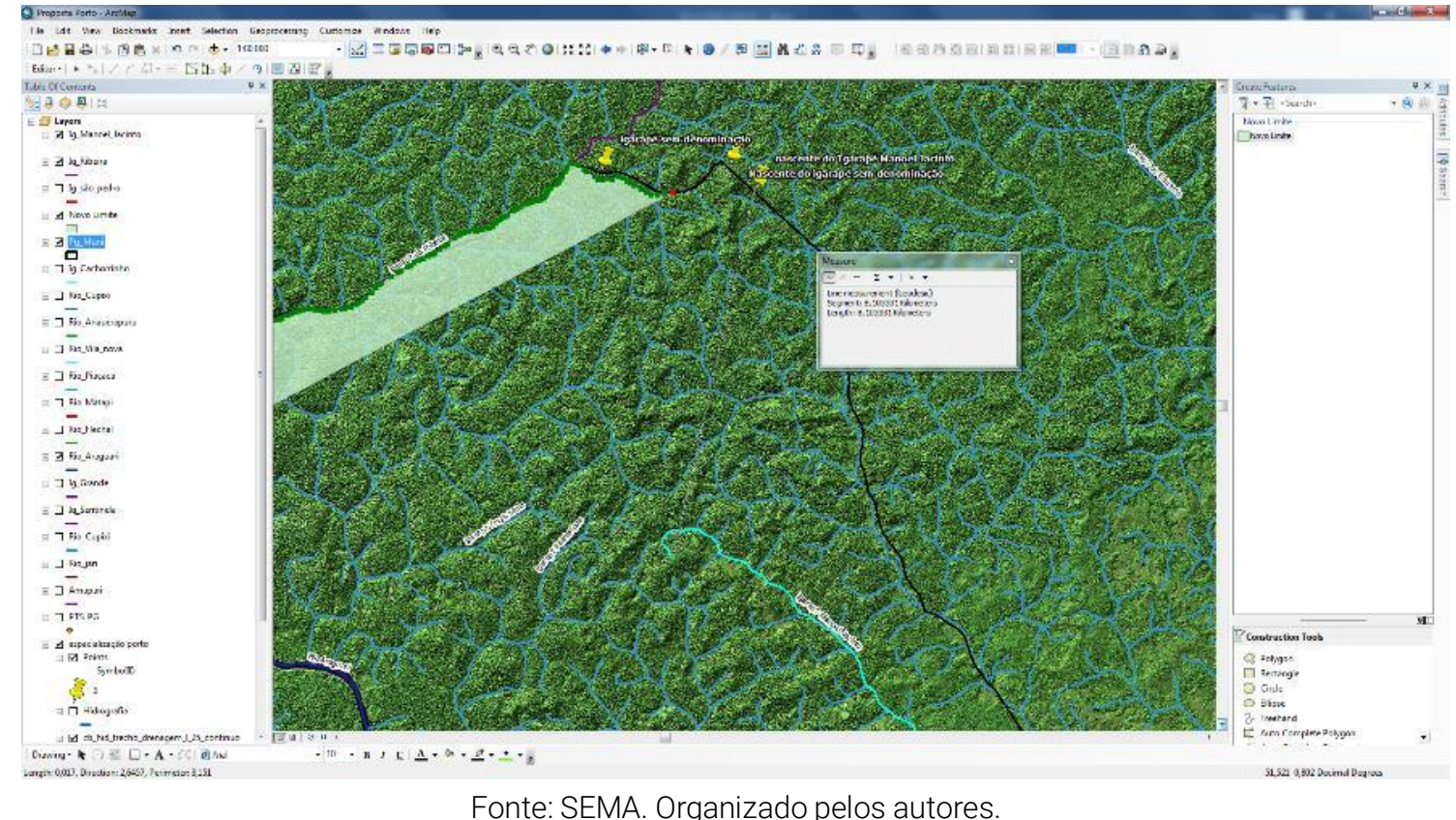


Após a espacialização completa do município (Figura 4), foi notado a poligonal do município mudaria pouco devido as inconsistências do memorial descritivo do município, fazendo com que o município fique com uma área maior do que a atual.

Figura 4 - Poligonal espacializada e poligonal em acordo com os limites do IBGE

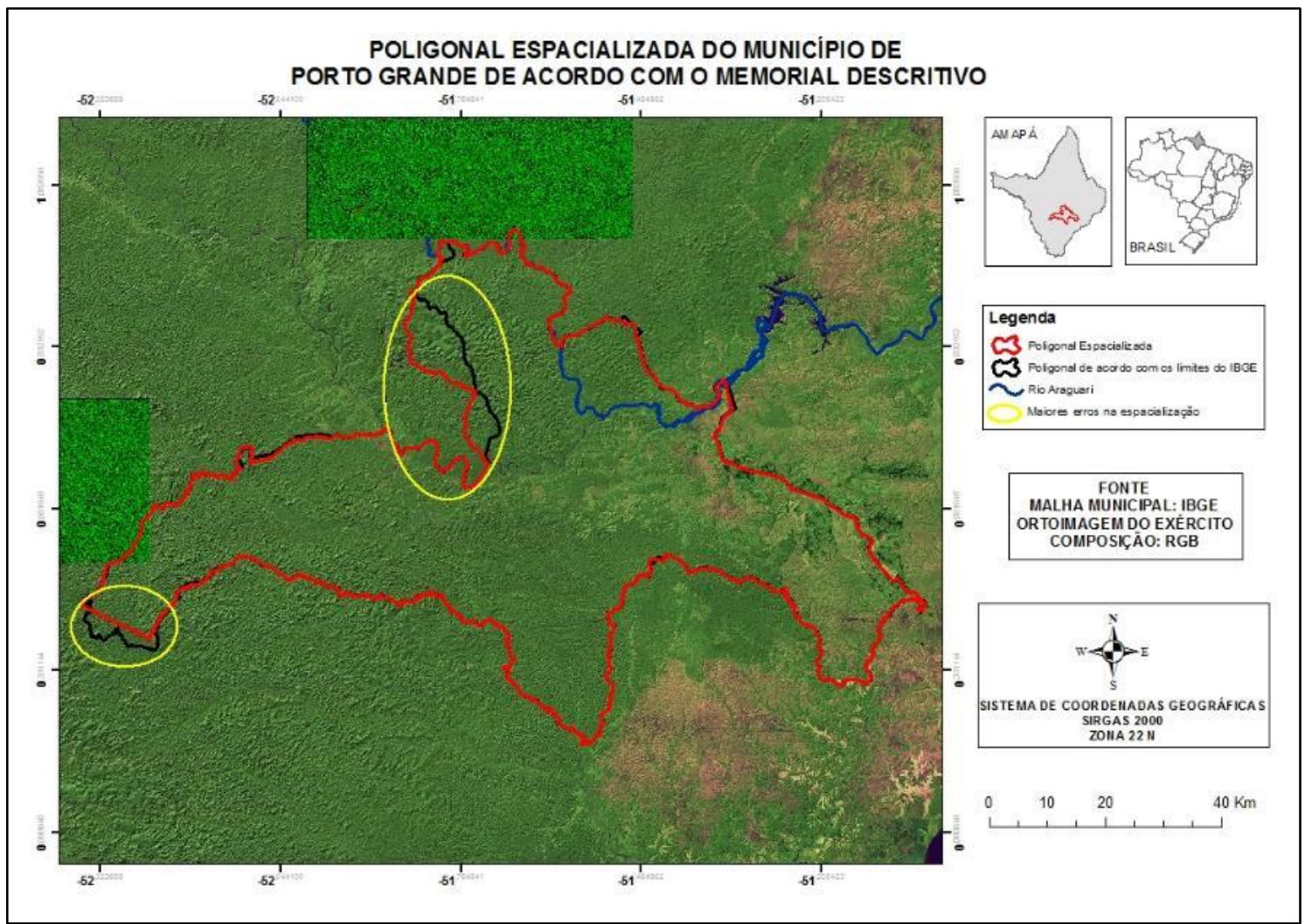

Fonte: Organizado pelos autores.

\section{Análise do memorial descritivo do município de Amapá}

O município de Amapá foi criado a partir da Lei n 3.055 de 22 de dezembro de 1956, outros municípios surgiram após essa data, que é o caso do município de Pracuúba, que na sua criação pegou parte do território do município de Amapá, fazendo com que diminuísse a área territorial do mesmo. Entretanto o memorial descritivo do município de Amapá não foi atualizado após a criação do município de Pracuúba, impossibilitando assim, a conclusão da poligonal do município.

Como pode ser observado no seguinte trecho do memorial: "...segue pelo referido rio Araguari até a confluência do rio Mutum", a partir da espacialização foi identificado que a confluência a que o memorial se refere está a 174,89 km de distância do atual limite (figura 5). 
Figura 5 - Distância entre a confluência do rio Mutum e o atual limite

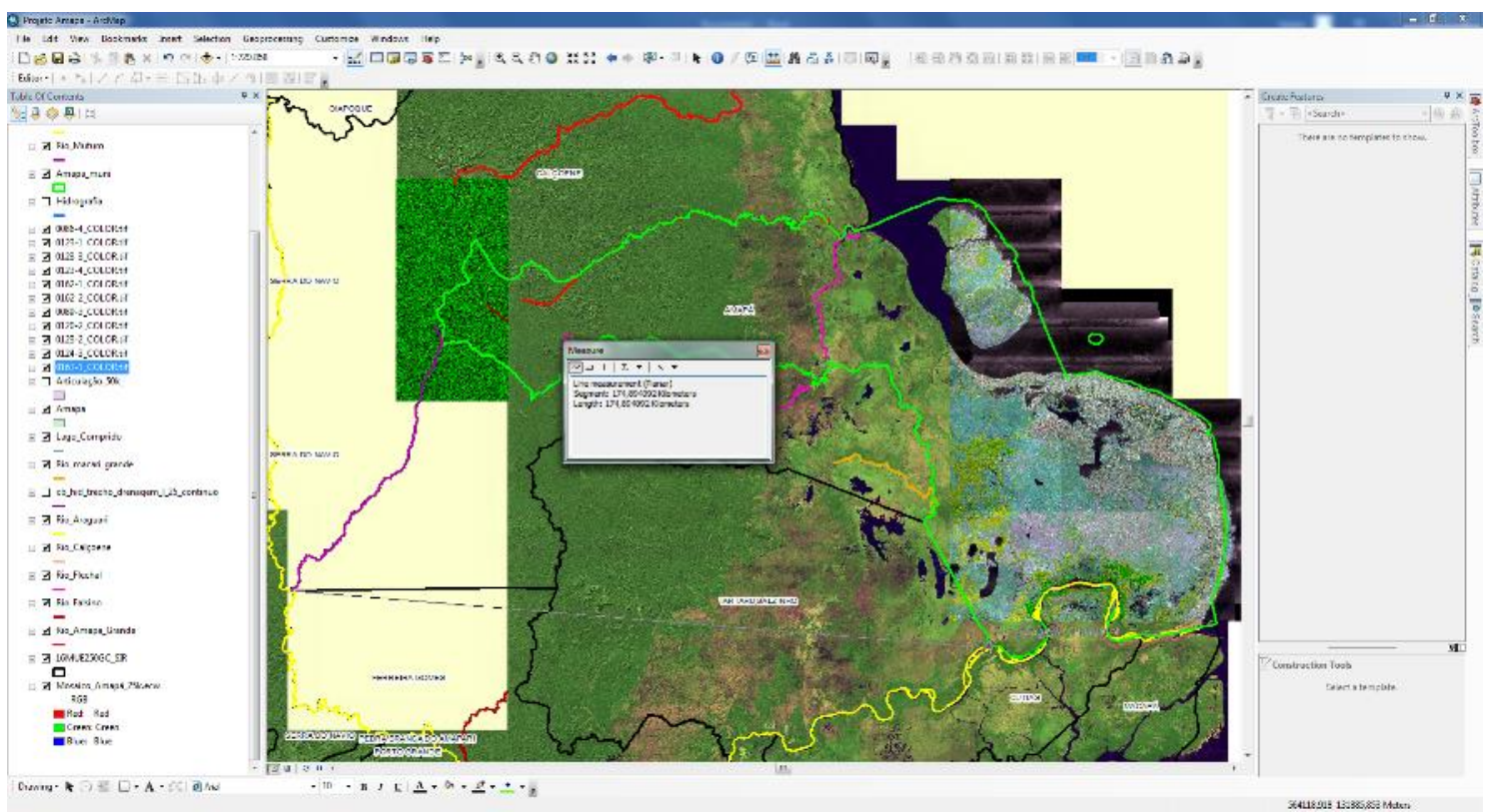

Fonte: SEMA. Organizado pelos autores.

Inviabilizando ainda mais a espacialização do município, o seguinte trecho do memorial: "...começa na foz do rio Mutum, no rio Araguari. Deste ponto por uma reta, atinge o divisor de águas dos rios Calçoene, Amapá grande, Flexal, Falsino e Mutum". Foi constatado que esta referência não está de acordo com o atual limite, pois como pode ser observado na figura 6, a foz do rio Mutum está a $72,47 \mathrm{~km}$ do atual limite.

Figura 6 - Distância entre a foz do rio Mutum e o atual limite

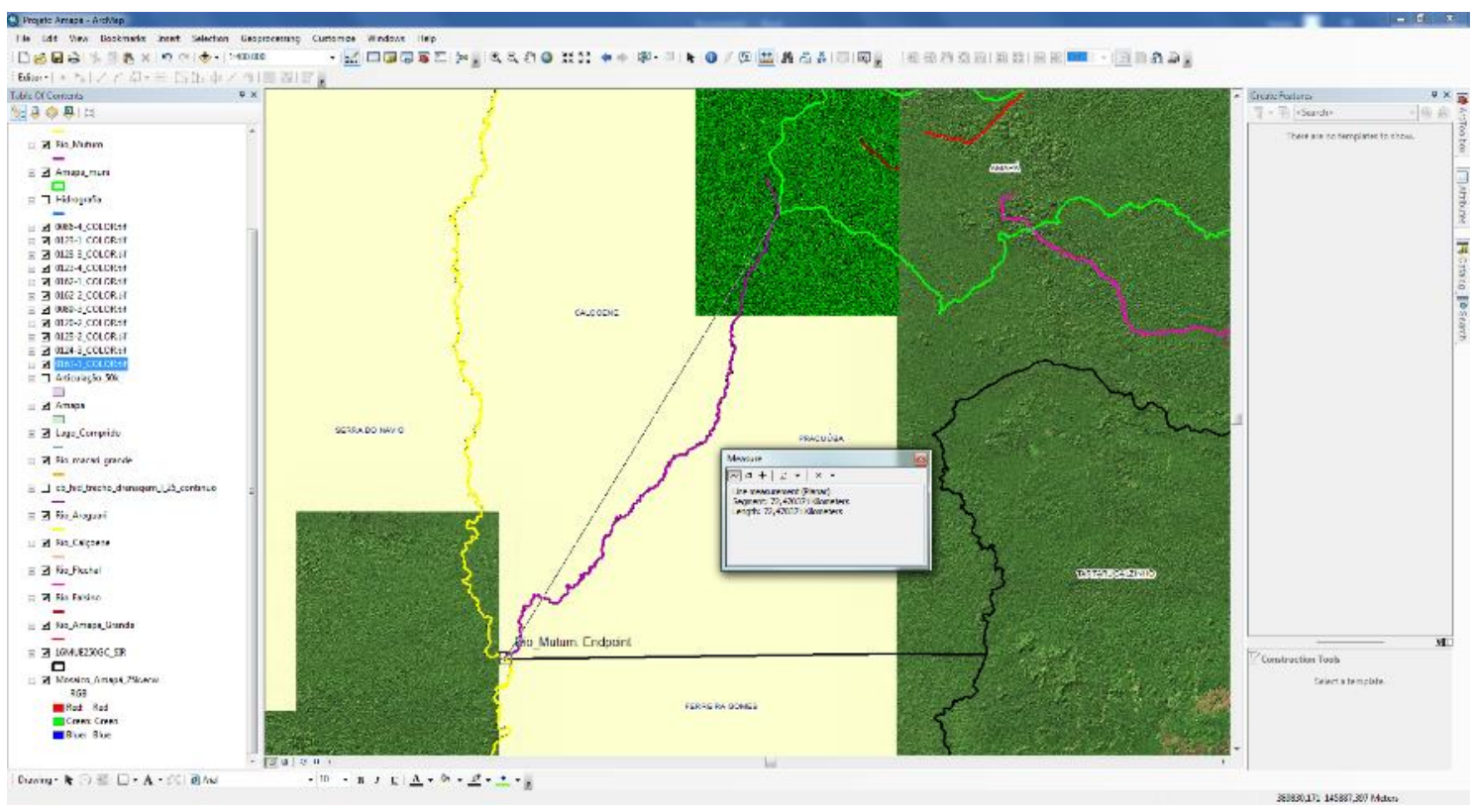

Fonte: SEMA. Organizado pelos autores. 


\section{Análise do memorial descritivo do município de Calçoene}

Assim como o município de Amapá, o memorial descritivo do município de Calçoene data de 22 de dezembro de 1956, com a Lei n 3,055. No decorrer da sua espacialização foram encontradas algumas inconsistências que alteram razoavelmente a sua atual poligonal, como: "Começa no divisor de águas do rio Araguari e a vertente direita do rio Oiapoque, no ponto mais próximo a cabeceira principal do rio Araguari; segue pelo referido divisor até alcançar a cabeceira principal do rio Cassiporé; daí, segue pelo rio Cassiporé abaixo até sua foz no oceano Atlântico". A partir da espacialização detectou-se o problema através da imagem da imagem de satélite e da base cartográfica de hidrografia, onde foi identificado que o atual limite segue um rio sem denominação (figura 7), e não o rio Cassiporé a qual se refere o memorial descritivo.

Figura 7 - Erro identificado no memorial descritivo

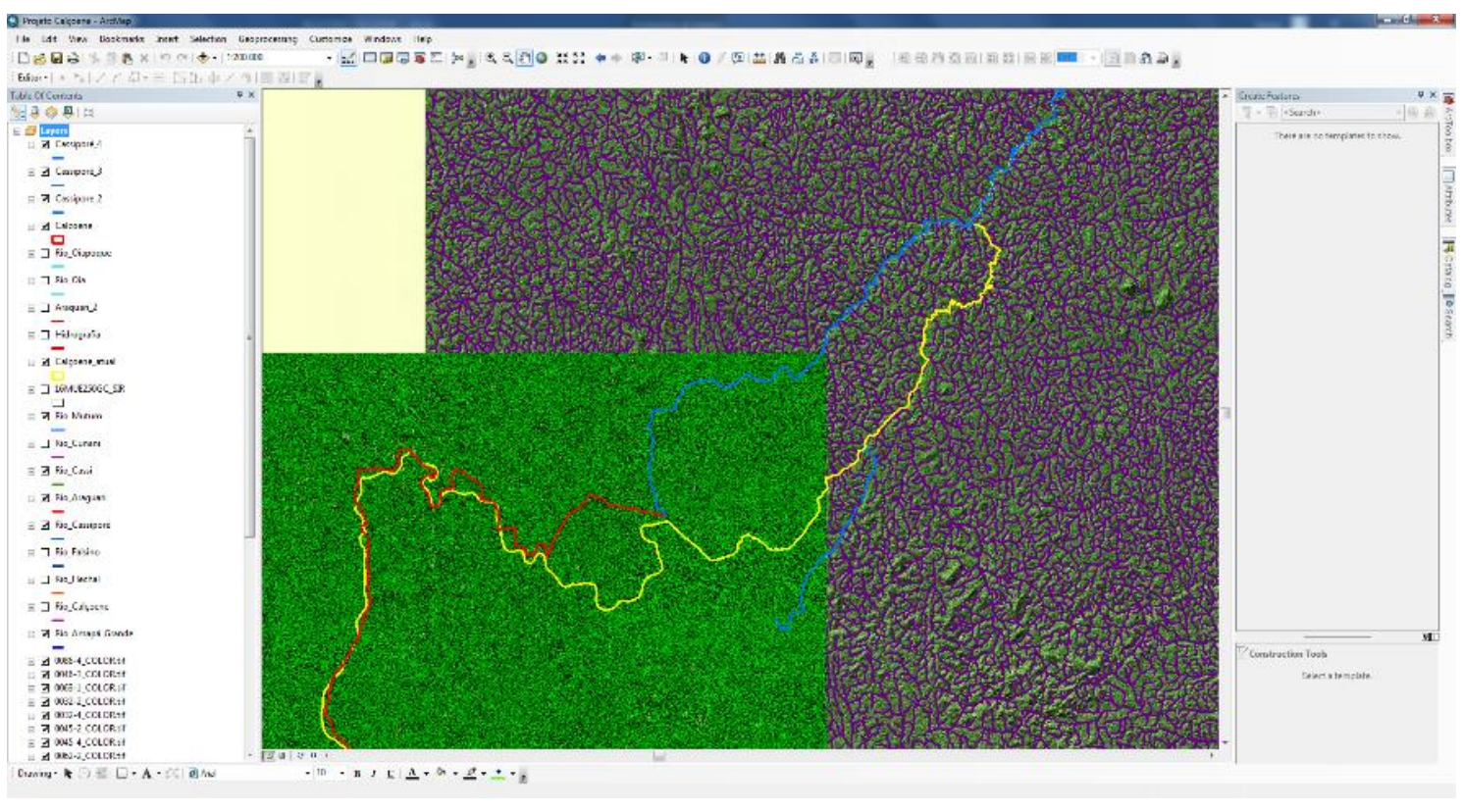

Fonte: SEMA. Organizado pelos autores.

Após a finalização do traçado completo do município (figura 8), seguindo as delimitações do memorial descritivo foi notado as alterações do atual limite para o espacializado seguindo as demarcações do memorial descritivo. 
Figura 8 - Poligonal espacializada e poligonal em acordo com os limites do IBGE

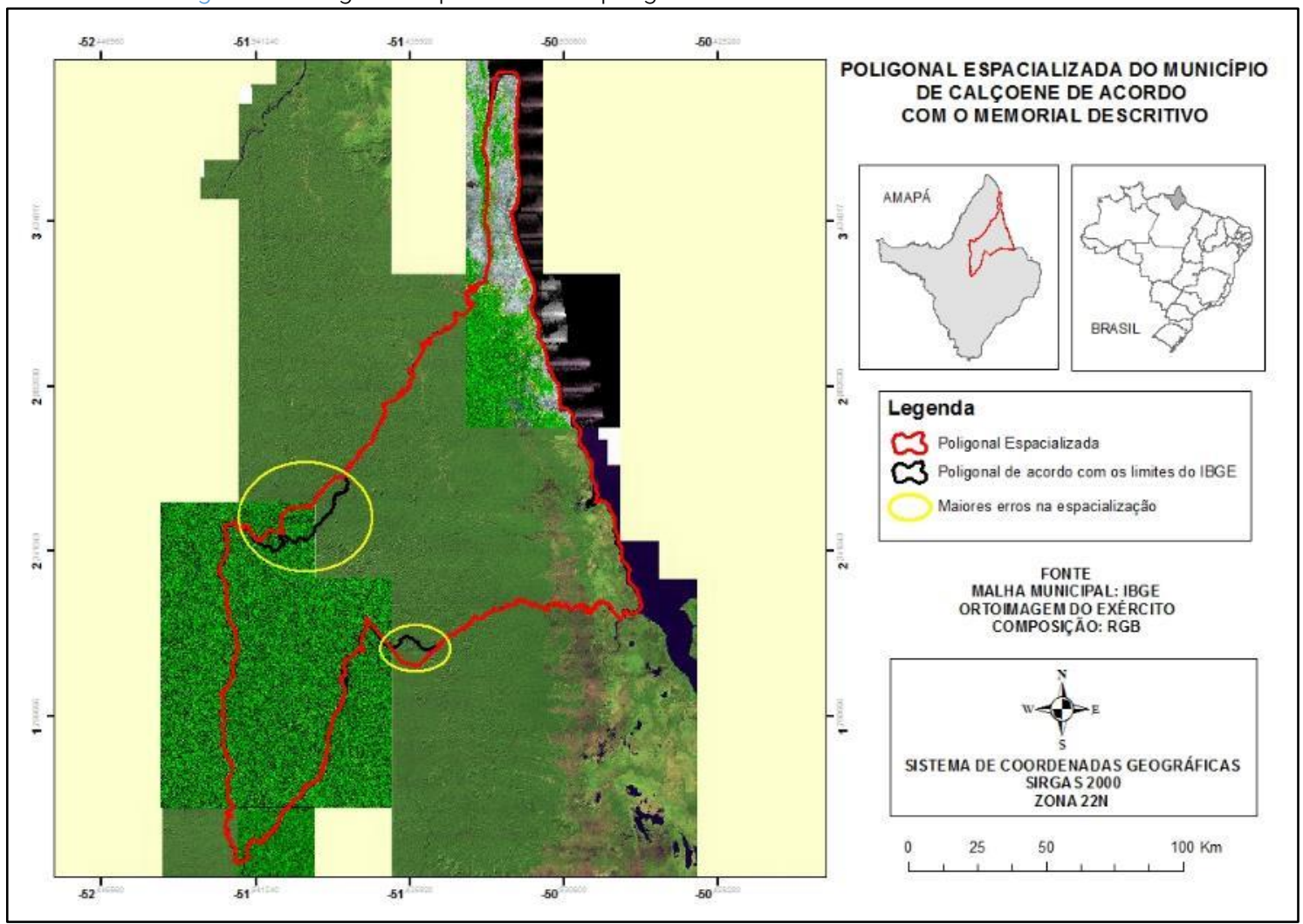

Fonte: organizado pelos autores.

Na tabela 1, é possível observar o tamanho da área em $\mathrm{km}^{2}$ tanto da área reconhecida atualmente pelo IBGE, como da área espacializada seguindo o memorial descritivo dos municípios de Porto Grande e Calçoene. A área do município de Amapá não se encontra na tabela, pois, o mesmo não foi possível de espacializar, mas de acordo com o IBGE (2019) o município possui uma área de $8.454,847 \mathrm{~km}^{2}$.

Tabela 1 - Tamanho da área dos municípios de Porto Grande e Calçoene

\begin{tabular}{ccc}
\hline Município & $\begin{array}{c}\text { Tamanho da área de acordo } \\
\text { com o IBGE }\end{array}$ & $\begin{array}{c}\text { Tamanho da área depois } \\
\text { de espacializada }\end{array}$ \\
\hline Porto Grande & $4.428,013 \mathrm{Km}^{2}$ & $4.530,665 \mathrm{Km}^{2}$ \\
\hline Calçoene & $14.117,297 \mathrm{Km}^{2}$ & $14.535,896 \mathrm{Km}^{2}$ \\
\hline
\end{tabular}

\section{Conclusões}

$\mathrm{Na}$ análise dos memoriais descritivos que definem os limites municipais, foram encontradas graves inconsistências nas leis de criação que não são possíveis de serem refletidas no espaço, processos antiquados de levantamentos são responsáveis por muitas destas inconsistências, contudo, são relevados, pois as leis datam em sua maioria da década de 50, entretanto, municípios criados na década de 90 apresentam problemas da mesma magnitude. 
A ação de revisão municipal é de fundamental importância para a gestão do território estadual e deve ser revisada periodicamente. As ferramentas de SIG se mostraram essenciais para a gestão dos limites, que com o passar do tempo evoluem a uma melhor delimitação do território.

A integração das técnicas de geoprocessamento com os recursos da cartografia permitiu o manuseio e a análise de informações de modo sistêmico, garantindo a construção de um modelo de representação espacial muito próximo da realidade. Foi identificado que os métodos de cartografia e geoprocessamento se mostraram instrumentos adequados para fornecer subsídios as diferentes instâncias do planejamento municipal relacionadas à gestão dos limites territoriais.

A análise dos memoriais descritivos e a espacialização dos 3 municípios apresentados no trabalho demonstram que a principal dificuldade no traçado dos limites territoriais dos municípios é a imprecisão do produto cartográfico que consta nos memoriais.

É preciso ressaltar que a indefinição de limites implica em problemas relevantes para os municípios. A ação de revisão dos limites municipais é instrumento fundamental para a gestão do território estadual e deve ser revisada periodicamente, os erros identificados na espacialização dos municípios mostram que não há muita preocupação por parte do Estado em relação aos limites municipais, visto isso, o problema de limites necessita de solução e instrumentos adequados para sua realização. 


\section{Referências}

AMAPÁ. Lei 0003 de 01 de maio de 1992. Diário Oficial do Estado de Amapá, Macapá, 1992.

AMAPÁ. Lei 3055 de 22 de dezembro de 1956. Diário Oficial do Estado do Amapá, Macapá, 1956.

AMAPÁ. Lei 3055 de 22 de dezembro de 1956. Diário Oficial do Estado do Amapá, Macapá, 1956.

BORGES, A. F.; ELMIRO, M. A. T.; NERO, M. A.; TEMBA, P. C.; SLTARELLI, C. C. Métodos de cartografia e geoprocessamento aplicados na gestão de inconsistências de limites intermunicipais - estudo de caso entre Nova Lima e Belo Horizonte, MG. Geografias Artigos Científicos, v. 11, n. 2, Belo Horizonte, 2015.

DRUMMOND, J. A.; PEREIRA, M. A. P. O Amapá nos tempos do manganês: um estudo sobre o desenvolvimento de um estado amazônico 1943-2000. Editora Garamond, 2007.

FERREIRA, Ricardo Vicente. Utilização de Sistemas de Informações Geográficas na Identificação de Unidades Geoambientais no Município de Analândia - SP. Dissertação (Mestrado em Geografia), Campinas, 2005.

Instituto Brasileiro de Geografia e Estatística - (IBGE) 2019. Disponível em: https://www.ibge.gov.br/cidades-e-estados/ap/amapa.html. Acesso em: 15 de abril de 2019.

MACEDO, M. R. A.; ROCHA, J. F.; SANTOS, C. A.; MIRANDA, R. S. Revisão dos limites municipais do estado do Pará com uso das geotecnologias. Anais do XVI Simpósio Brasileiro de Sensoriamento Remoto, Foz do Iguaçu, 2013.

SILVA, E. S.; CAMBOIM, S. P. Proposta de um sistema de limites municipais. Revista Brasileira de Cartografia, Rio de Janeiro de 2017.

VIEIRA, M. S. Base cartográfica contínua do estado do Amapá. Históriafgmbcp, p. 47, 2015. 